\title{
The addition of droperidol or clonidine to epidural tramadol shortens onset time and increases duration of postoperative analgesia
}

\author{
[L'addition de dropéridol ou de clonidine à l'administration péridurale de tramadol \\ raccourcit le délai d'installation et prolonge la durée de l'analgésie postopératoire]
}

Ercan Gürses MD, Hülya Sungurtekin MD, Erkan Tomatir MD, Canan Balci MD, Mustafa Gönüllü MD

Purpose: To compare tramadol alone and the combinations of either tramadol-clonidine or tramadol-droperidol with regard to analgesic and adverse effects.

Methods: After Ethic's Committee approval and patient informed consent were obtained, epidural catheters were inserted preoperatively at the $L_{3-4}$ interspace in 90 ASA physical status I-II adult patients undergoing lower abdominal surgery. Anesthesia was standardized. Patients were randomly assigned to one of three groups. Group I (T) patients received tramadol 75 mg, Group II (TD) patients received tramadol $75 \mathrm{mg}$ plus droperidol $2.5 \mathrm{mg}$, and Group III (TC) patients received tramadol 75 mg plus clonidine 150 $\mu \mathrm{g}$ in a total volume of $10 \mathrm{~mL}$ administered as a single epidural injection in the postanesthesia care unit. The onset time of analgesia and duration of analgesia, visual analogue pain scores, sedation, nausea scores, vital signs and side effects were recorded.

Results: Duration of analgesia was similar in both the TD and TC groups, and significantly longer than in the $T$ group $(P<0.00 \mathrm{I})$. Group TC patients displayed a significant increase in sedation scores and decrease in blood pressure and heart rate when compared with other groups $(P<0.001)$. No adverse effects were observed in Group TD, while nausea scores were high in both the T and TC groups $(P<0.00 \mathrm{I})$. Pain score, respiration rate, and $\mathrm{SpO}_{2}$ values were similar in all study groups.

Conclusion: We conclude that epidural tramadol in combination with droperidol or clonidine prolongs the duration of analgesia; however, droperidol appears to be a better alternative when adverse effects and antiemetic properties are taken into consideration.
Objectif : Comparer le tramadol à la combinaison de tramadol-clonidine ou de tramadol-dropéridol en regard de leurs effets analgésiques et indésirables.

Méthode : Ayant obtenu l'approbation du Comité d'éthique et le consentement éclairé des patients, nous avons réalisé l'insertion préopératoire d'un cathéter péridural dans l'espace intercostal $L_{3-4}$ chez 90 patients adultes d'état physique ASA I-II devant subir une intervention abdominale basse. L'anesthésie a été normalisée. Les patients ont été répartis en trois groupes de façon aléatoire. Ceux du groupe I (T) ont reçu 75 mg de tramadol, ceux du groupe II (TD), 75 mg de tramadol et 2,5 mg de dropéridol et du groupe III (TC), 75 mg de tramadol plus $150 \mu \mathrm{g}$ de clonidine dans un volume total de $10 \mathrm{~mL}$ administré à la salle de réveil en une seule injection péridurale. Le délai d'installation et la durée de l'analgésie, la douleur selon l'échelle visuelle analogique, la sédation, les nausées, les signes vitaux et les effets secondaires ont été notés.

Résultats : La durée de l'analgésie a été comparable entre les groupes TD et TC et significativement plus longue que dans le groupe $T(P<$ $0,001)$. Les patients du groupe TC, comparés à ceux des autres groupes, ont connu une hausse significative des scores de sédation et une baisse de la tension artérielle et de la fréquence cardiaque $(P<$ 0,00 I). Aucun effet indésirable r'a été observé dans le groupe TD tandis que les scores de nausées ont été plus élevés dans les groupes $T$ et TC $(P<0,001)$. Les scores de douleur, la fréquence respiratoire et la $\mathrm{SpO}_{2}$ ont présenté des valeurs similaires dans tous les groupes de l'étude. Conclusion : Nous pouvons conclure que l'administration péridurale de tramadol, combinée au dropéridol ou à la clonidine, prolonge la durée de l'analgésie ; cependant, le dropéridol semble un meilleur choix quand on considère les effets indésirables et les propriétés antiémétiques.

From the Department of Anesthesiology, Pamukkale University Faculty of Medicine, Denizli, Turkey. Address correspondence to: Dr. Ercan Gürses, Atakent Mahallesi, Esnaf Sitesi Zambak Sokak, No: 8, Yenisehir, 20045 Denizli, Turkey.

Phone: +90-258-241 00 34/113; +90-258-373 58 38; Fax: +90-258-373 13 42; E-mail: elgurses@pamukkale.edu.tr Accepted for publication May 27, 2002.

Second revision accepted November 4, 2002. 
$\mathrm{E}$ PIDURAL opioid administration is one of the most common techniques for postoperative pain control. Epidural administration of low dose opioids provides strong and long lasting segmental analgesia via opioid receptors. ${ }^{1}$ However, the known adverse effects of epidural opioids require a very careful selection of the agent and dosage. Although epidural morphine, fentanyl, alfentanil and pethidine provide effective analgesia and are associated with a low systemic redistribution, the risk of respiratory depression increases with repeated and continuous administration of epidural opioids. Tramadol may be advantageous because of a low risk of respiratory depression. ${ }^{2,3}$ Tramadol is a weak agonist at all types of opioid receptors with some selectivity for $\mu$ receptors. Also, tramadol inhibits the reuptake of norepinephrine and serotonin, thus increasing the concentrations of these two neurotransmitters in the central nervous system.

In clinical studies, spinal or epidural administration of non-opioid agents such as clonidine, droperidol, neostigmine, ketamine, midazolam, somatostatine and calcitonin have been shown to provide analgesia without causing motor dysfunction or neurotoxicity. ${ }^{4-8}$ Epidural droperidol blocks mainly the fast, and to a lesser extent, the slow sodium channels and inhibits the formation of action potential. Clonidine, which is an alpha ${ }_{2}$ adrenergic agonist, has an anti-nociceptive effect on a wide dynamic range of neurons and $\delta$ receptors. Although they cannot provide sufficient analgesia by themselves, when used as adjuncts to lowdose opioids, they decrease adverse effects, and increase the quality and duration of analgesia. ${ }^{9-14}$

At present, there is no ideal drug or combination of drugs for postoperative epidural analgesia. The present study was conducted to compare the analgesic and adverse effects (sedation, nausea, vomiting and hemodynamic changes) of epidural tramadol used alone, and the combinations of tramadol-droperidol and tramadol-clonidine.

\section{Methods}

After obtaining approval from the local Ethics Committee and written informed consent, 90 patients aged 20-68 yr, ASA physical status I and II, scheduled for elective total abdominal hysterectomy, were selected for this prospective, randomized and double-blind study. Randomization was performed by using computer generated random numbers, kept in consecutively numbered and sealed envelopes. Exclusion criteria were a history of cardiovascular, respiratory, or central nervous system diseases, bleeding disorders, use of opioids and drugs that affect the central ner-
TABLE I Sedation scores ${ }^{15}$

0 Alert or drowsy but easily aroused to an alert state by verbal commands alone

1 Sleeping and arousable by verbal commands

2 Sleeping and not aroused by verbal stimuli, but aroused to a drowsy state by tactile stimulation

3 Sleeping and not aroused to a drowsy state by tactile stimulation

TABLE II Nausea and vomiting scores ${ }^{16}$

\begin{tabular}{ll}
\hline 0 & No nausea/vomiting \\
1 & Mild nausea/vomiting (patient not requesting an antiemetic) \\
2 & Nausea/vomiting patient requesting an antiemetic \\
3 & Nausea/vomiting, resistant to antiemetic \\
\hline
\end{tabular}

TABLE III Demographic data and duration of surgery (mean \pm SD)

\begin{tabular}{llll}
\hline & $T(n=30)$ & $T D(n=30)$ & $T C(n=30)$ \\
\hline Age $($ year $)$ & $53.8 \pm 9.4$ & $51.3 \pm 9.1$ & $52.3 \pm 8.9$ \\
Body weight $(\mathrm{kg})$ & $64.5 \pm 10.8$ & $63.5 \pm 10.5$ & $64.7 \pm 11.0$ \\
Length $(\mathrm{cm})$ & $162.4 \pm 12.4$ & $160.2 \pm 11.9$ & $164.1 \pm 12.0$ \\
Sex $(\mathrm{M} / \mathrm{F})$ & $14 / 16$ & $12 / 18$ & $15 / 15$ \\
ASA $(\mathrm{I} / \mathrm{II})$ & $30 / 0$ & $28 / 2$ & $28 / 2$ \\
Duration of & & & \\
surgery $(\mathrm{min})$ & $92.5 \pm 9.0$ & $91.9 \pm 8.8$ & $92.7 \pm 9.3$ \\
\hline
\end{tabular}

$\mathrm{T}=$ tramadol alone $; \mathrm{TD}=$ tramadol-droperidol; $\mathrm{TC}=$ tramadol clonidine.

vous system (mono amine oxydase inhibitors, carbamazepine, quinidine and cimetidine), difficulty of cooperation and pregnant patients.

All patients were taken into the operating room unpremedicated. After standard monitoring with noninvasive blood pressure, electrocardiography and peripheral oxygen saturation $\left(\mathrm{SpO}_{2}\right)$, administration of Lactated Ringer's solution was started. Patients were positioned in the lateral decubitus and a $20-\mathrm{G}$ epidural catheter (Perifix 401, B.Braun, Melsungen AG) was inserted through an 18-gauge Tuohy needle at the $\mathrm{L}_{3-4}$ interspace. The same anesthesiologist (E.G.) inserted all epidural catheters. After injection of $2 \mathrm{~mL} 0.5 \%$ bupivacaine with $15 \mu \mathrm{g}$ adrenalin through the epidural catheter as a test dose, the catheter was fixed and the patient was repositioned supine. Induction of anesthesia was achieved with propofol $\left(2 \mathrm{mg} \cdot \mathrm{kg}^{-1}\right)$ and cisatracurium $\left(0.2 \mathrm{mg} \cdot \mathrm{kg}^{-1}\right)$. The trachea was intubated and the lungs ventilated mechanically. Anesthesia was maintained with an $\mathrm{O}_{2} / \mathrm{N}_{2} \mathrm{O}$ mixture $(50 \%: 50 \%)$, isoflurane and cis-atracurium. 


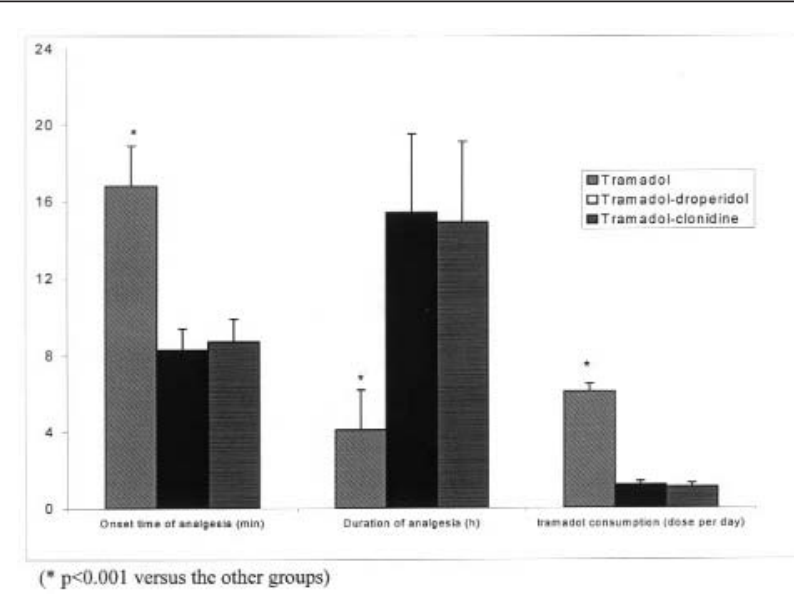

FIGURE 1 Onset time and duration of analgesia and tramadol consumption in number of doses required in $24 \mathrm{hr}$.

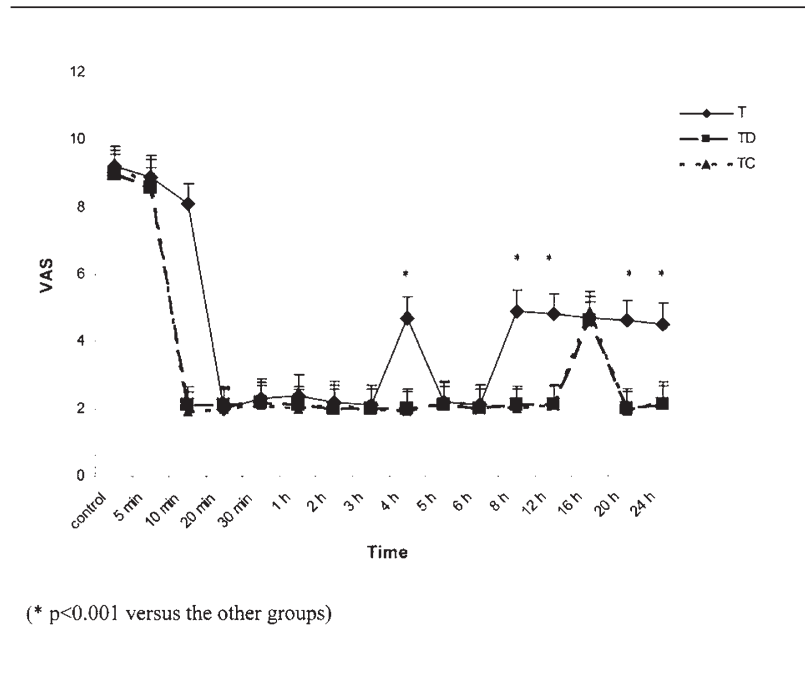

FIGURE 2 Visual analogue scale (VAS) after surgery.
The intensity of postoperative pain was measured with the visual analogue scale (VAS). Sedation was monitored on a four-point scale (Table I) ${ }^{15}$ and nausea was monitored on a four-point scale (Table II). ${ }^{16}$ The onset time of analgesia, duration of analgesia and total tramadol dose were recorded. The onset time of analgesia was defined as the time required to decrease the VAS score control value by $20 \mathrm{~mm}$, and duration of analgesia as the increase of VAS score value by 20 $\mathrm{mm}$. The need for additional tramadol or TC/TD was defined as an increase in the VAS pain score of $20 \mathrm{~mm}$ or more. Total tramadol consumption during the last $24 \mathrm{hr}$ is reported in all patients. Vital signs (respiratory rate, $\mathrm{SpO}_{2}$, heart rate, blood pressure), sedation and nausea scores, VAS pain scores and adverse effects were assessed before injection, and at five, ten, 20, 30 min, one, two, three, four, five, six, eight, 12, 16, 20, and $24 \mathrm{hr}$ after epidural injection. In cases of VAS scores $5 \mathrm{~cm}$ at rest $30 \mathrm{~min}$ after epidural injection, patients were given $1 \mathrm{mg} \cdot \mathrm{kg}^{-1}$ meperidine $\mathrm{im}$. When nausea and vomiting were $\geq 2$, patients were given metoclopramide $10 \mathrm{mg} i v$. Hypotension, defined as a reduction of the systolic blood pressure $>20 \%$, was treated with the rapid infusion of lactated Ringer's solution and $i v$ boluses of ephedrine. All postoperative assessments were made by an investigator blinded to study group.

Previous studies have determined that the effective dose of epidural tramadol for postoperative analgesia ranges from 75 to $200 \mathrm{mg}$. With a level of $\alpha 0.05$ and $\beta$ level of 0.2 , power analysis indicated that 30 observations would be needed to detect clinically relevant differences in tramadol consumption. A $50 \%$ decrease in the tramadol consumption in the treatment groups would be of clinically relevance. ${ }^{17}$ Intergroup comparison of demographic data was made by Student's t test. The three groups were compared by Mann Whitney U test for non-parametric data. Comparison was made by one-way analysis of variance (ANOVA) followed by a Student's $t$ test for parametric data. Results were expressed as mean \pm standard deviation. A value of $P<$ 0.05 was considered statistically significant.

\section{Results}

The three groups of patients were similar with respect to demographic data, ASA physical status and duration of surgery (Table III). The onset time of analgesia was $16.8 \pm 2.1 \mathrm{~min}, 8.3 \pm 1.1 \mathrm{~min}$, and $8.7 \pm 1.2$ $\mathrm{min}$ in the $\mathrm{T}, \mathrm{TD}$, and $\mathrm{TC}$ groups, respectively. It was longer in the T group than in the TD and TC groups $(P<0.001)$. Patients in the T group displayed shorter durations of analgesia than in the other groups (4.1 $\pm 2.1 \mathrm{hr}, 15.4 \pm 4.1 \mathrm{hr}$, and $14.9 \pm 4.2 \mathrm{hr}$ in $\mathrm{T}, \mathrm{TD}$, 


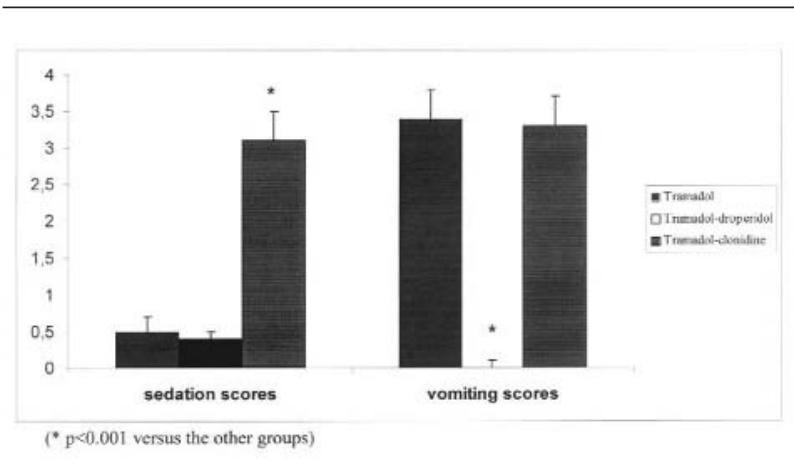

FIGURE 3 Sedation and nausea/vomiting scores ten minutes after epidural injection.

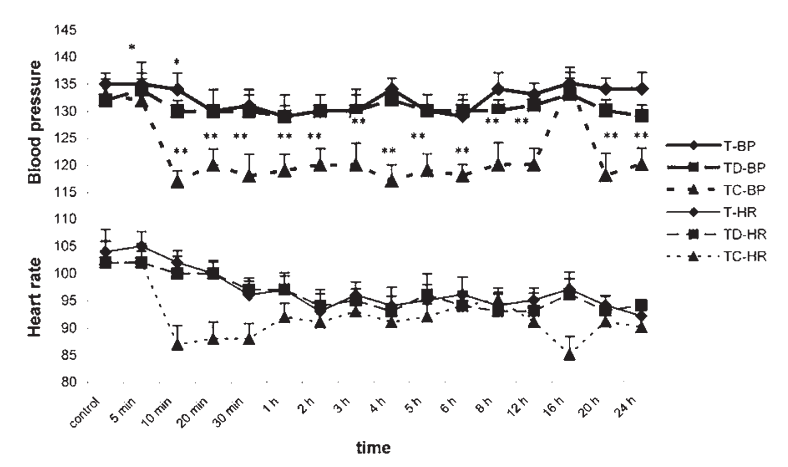

$\left({ }^{*} \mathrm{p}<0.05,{ }^{* *} \mathrm{p}<0.01\right.$ versus the control measurement of the groups)

FIGURE 4 Systolic blood pressure and heart rate in the postoperative period $($ mean $\pm \mathrm{SD})$.

and TC groups respectively; $P<0.001)$. Tramadol consumption (doses per day) was higher in the $\mathrm{T}$ group than in the TD and TC groups $(P<0.001)$. Tramadol consumption was $457.5 \pm 16.7 \mathrm{mg}, 90 \pm$ $8.2 \mathrm{mg}$, and $82.5 \pm 8.9 \mathrm{mg}$ in the T, TD and TC groups respectively (Figure 1).

VAS pain scores in the $\mathrm{T}$ group were significantly higher when compared with the other groups at four, eight, 12, 20 and $24 \mathrm{hr}(P<0.001)$. No difference was found for the VAS score at the $16^{\text {th }} \mathrm{hr}$. No patient required meperidine (Figure 2 ).

Group T and TD patients did not show any sedation, however group TC patients had increased sedation scores at ten minutes (Figure $3 ; P<0.001$ ). Patients in the T and TC groups had higher nausea scores than those in the TD group at ten minutes $(P$ $<0.001$; Figure 3 ). There was no statistical significant difference for nausea/vomiting and sedation scores at the other time points. The incidence of nausea and vomiting ten minutes after epidural injection was $24 \%$, $0.1 \%$, and $22 \%$ in the T, TD and TC groups respectively. Six patients in the T group and seven patients in the TC group received metoclopramide for nausea and vomiting.

Blood pressure and heart rate were not different from control in the T and TD groups. Patients in the TC group showed a decrease of $10 \%(P<0.01)$ in blood pressure and of $6 \%(P<0.05)$ in heart rate beginning ten minutes after injection until the end of the study (Figure 4). Respiratory rate and $\mathrm{SpO}_{2}$ values were within normal ranges in all patients.

\section{Discussion}

Mean onset time of analgesia has been reported as 10-15 min for epidural tramadol and 5-11 min for the tramadol-droperidol combination. ${ }^{2,16,18}$ Furthermore, it has been stated that a combination of clonidine with fentanyl, sufentanil and morphine decreases the onset time of analgesia by $50 \%{ }^{4,19,20}$ Consistent with previous reports, the present study shows that the onset time of analgesia was 16 min time with tramadol alone and that this time decreased to approximately eight minutes when either clonidine or droperidol was added.

The mean durations of analgesia have been reported as being four to six hours for tramadol alone and 12-16 hr for the tramadol-droperidol combination, where the number of daily doses were six to eight for the tramadol alone and one to two for the tramadoldroperidol combination. ${ }^{2,9,16}$ It has been suggested that the combination of clonidine with an opioid extends the duration of analgesia by two to three times. ${ }^{1,4,10,15,21}$ Murthy et al. ${ }^{22}$ have found a lower volume of distribution for epidural tramadol and stated that the half-life was shorter than with $i v$ usage. In the present study, we observed that the addition of clonidine or droperidol to tramadol extends the duration of analgesia by three times on average and, consequently, reduces daily tramadol requirements.

Studies using tramadol and tramadol-droperidol combinations found no significant sedation, ${ }^{2,3,9,16,18}$ while all studies using clonidine have reported a prominent increase in sedation. . $^{1,10,15,19}$ This leads us to believe that the significant increase in sedation observed in the tramadol-clonidine group was due to the addition of clonidine.

Although the studies using epidural clonidine have reported bradycardia and hypotension as the most frequent adverse effects, ${ }^{1,4,10,15,19}$ no significant hemody- 
namic adverse effects have been reported with tramadol alone or with the tramadol-droperidol combination. ${ }^{1-3,12,16,18}$ We observed a decrease in blood pressure and heart rate from the tenth minute onwards only in the tramadol-clonidine group. This decrease did not require any intervention and no such adverse effect was detected in the other groups.

Low plasma concentrations of tramadol are observed after epidural injection, and these are insufficient to produce an analgesic effect. ${ }^{2}$ Therefore, despite the lack of a parenteral control group, we believe that the analgesic effect of tramadol was mediated epidurally.

The most frequent side effect of epidural tramadol is nausea. The addition of droperidol to epidural opioids has a strong antiemetic effect. ${ }^{1,4,15,23}$ In the present study, nausea was the most frequent adverse effect in the tramadol and tramadol-clonidine groups and, since no significant difference was detected between the two groups, we conclude that nausea is probably secondary to tramadol. The absence of nausea in the tramadol-droperidol group is consistent with previous studies and might be related to the antiemetic effect of droperidol.

The main adverse effects of long-term epidural droperidol are sedation, anxiety, panic, suicide and extrapyramidal side effects. ${ }^{1}$ When used per oral, iv or epidural, droperidol has shown adverse effects such as QT prolongation and/or arrhythmia. ${ }^{24-26}$ The absence of adverse effects in the present study may be secondary to the brief duration of exposure, the low doses used and the small number of patients studied.

The safety of epidural and intrathecal clonidine has been established in several studies. ${ }^{1,10}$ No local or systemic toxic effects of epidural droperidol have been reported except for excessive sedation. ${ }^{1,8,12}$ Finally, no systemic or local neurotoxicity has been reported with the epidural injection of tramadol. ${ }^{1-3,6}$

In conclusion, our results suggest that the addition of droperidol or clonidine to epidural tramadol provides a shorter onset time and a longer duration of analgesia. Droperidol seems to be a more suitable adjunct when its adverse effects and antiemetic properties are taken into consideration.

\section{References}

1 Rawal N. Epidural and spinal agents for postoperative analgesia. Surg Clin North Am 1999; 79: 313-44.

2 Delilkan AE, Vijayan R. Epidural tramadol for postoperative pain relief. Anaesthesia 1993; 48: 328-31.

3 Baraka A, Jabour S, Ghabash $M$, Nader A, Khoury G, Sibai $A$. A comparison of epidural tramadol and epidural morphine for postoperative analgesia. Can J Anaesth 1993; 40: 308-13.
4 Armand S, Langlade A, Boutros A, et al. Meta-analysis of the efficacy of extradural clonidine to relieve postoperative pain: an impossible task. Br J Anaesth 1998; 81: 126-34.

5 Hood DD, Eisenach JC, Tuttle RN. Phase I safety assessment of intrathecal neostigmine methylsulphate in humans. Anesthesiology 1995; 82: 331-43.

6 Tsai YC, Chang PJ, Jou IM. Direct tramadol application on sciatic nerve inhibits spinal somatosensory evoked potentials in rats. Anesth Analg 2001; 92: 1547-51.

7 Olschewski A, Brau ME, Hempelmann G, Vogel W, Safronov $B V$. Differential block of fast and slow inactivating tetrodotoxin-sensitive sodium channels by droperidol in spinal dorsal horn neurons.

Anesthesiology 2000; 92: 1667-76.

8 Grip G, Svensson BA, Gordh T, Post C Jr, Hartvig P. Histopathology and evaluation of potentiation of morphine-induced antinociception by intrathecal droperidol in the rat. Acta Anaesthesiol Scand 1992; 36: 145-52.

9 Lewis KS, Han NH. Tramadol: a new centrally acting analgesic. Am J Health Syst Pharm 1997; 54: 643-52.

10 Motsch J, Graber E, Ludwig K. Addition of clonidine enhances postoperative analgesia from epidural morphine: a double-blind study. Anesthesiology 1990; 73: 1067-73.

11 Ferrante FM, VadeBoncouer TR. Postoperative Pain Management. New York: Churchill Livingstone; 1993: 641.

12 Naji P, Farschtschian M, Wilder-Smith OH, WilderSmith $\mathrm{CH}$. Epidural droperidol and morphine for postoperative pain. Anesth Analg 1990; 70: 583-8.

13 Raffa RB, Nayak RK, Liao S, Minn FL. The mechanism(s) of action and pharmacokinetics of tramadol hydrochloride. Rev Contemp Pharmacother 1995; 6: 485-97.

14 Desmeules JA, Piguet V, Collart L, Dayer P. Contribution of monoaminergic modulation to the analgesic effect of tramadol. Br J Clin Pharmacol 1996; 41: 7-12.

15 De Kock M, Wiederkher P, Laghmiche A, Scholtes JL. Epidural clonidine used as the sole analgesic agent during and after abdominal surgery. Anesthesiology 1997; 86: 285-92.

$16 \mathrm{Ng} \mathrm{KF}$, Tsui SL, Yang JC, Ho ET. Comparison of tramadol and tramadol/droperidol mixture for patientcontrolled analgesia. Can J Anaesth 1997; 44: 810-5.

17 Lerman J. Study design in clinical research: sample size estimation and power analysis. Can J Anaesth 1996; 43: 184-91.

18 Siddik-Sayyid S, Aouad-Maroun M, Sleiman D, Sfeir M, Baraka $A$. Epidural tramadol for postoperative pain 
after cesarean section. Can J Anesth 1999; 46: 731-5.

19 Owen MD, Ozsarac O, Sabin S, Uckunkaya N, Kaplan $N$, Magunaci I. Low-dose clonidine and neostigmine prolong the duration of intrathecal bupivacaine-fentanyl for labor analgesia. Anesthesiology 2000; 92: 361-6.

20 Eisenach JC, De Kock M, Klimscha W. Alpha 2 -adrenergic agonists for regional anesthesia. A clinical review of clonidine (1984-1995). Anesthesiology 1996; 85: 655-74.

21 Curatolo M, Schnider TW, Petersen-Felix S, et al. A direct search procedure to optimize combinations of epidural bupivacaine, fentanyl, and clonidine for postoperative analgesia. Anesthesiology 2000; 92: 325-37.

22 Murthy BV, Pandya KS, Booker PD, Murray A, Lintz

$W$, Terlinden $R$. Pharmacokinetics of tramadol in children after i.v. or caudal epidural administration. Br J Anaesth 2000; 84: 346-9.

23 Horta ML, Ramos L, Gonçalves ZR. The inhibition of epidural morphine-induced pruritus by epidural droperidol. Anesth Analg 2000; 90: 638-41.

24 Bailey $P$, Norton $R$, Karan $S$. The FDA droperidol warning: is it justified? (Letter). Anesthesiology 2002; 97: 288-9.

25 Kantor GS. Arrhythmia risk of antiemetic agents. Anesthesiology 2002; 97: 286.

26 Lischke V, Behne M, Doelken P, Schledt U, Probst S, Vettermann J. Droperidol causes a dose-dependent prolongation of the QT interval. Anesth Analg 2002; 79: 983 (abstract). 